\title{
Aircraft Requirements for Sustainable Regional Aviation
}

\author{
Dominik Eisenhut ${ }^{1, *,+} \mathbb{D}$, Nicolas Moebs ${ }^{1,+}{ }^{\mathbb{D}}$, Evert Windels ${ }^{2}$, Dominique Bergmann ${ }^{1}$, Ingmar Geiß ${ }^{1}$, \\ Ricardo Reis ${ }^{3}$ (D) and Andreas Strohmayer ${ }^{1}$ (D)
}

1 Institute of Aircraft Design, University of Stuttgart, 70569 Stuttgart, Germany; moebs@ifb.uni-stuttgart.de (N.M.); bergmann@ifb.uni-stuttgart.de (D.B.); geiss@ifb.uni-stuttgart.de (I.G.); strohmayer@ifb.uni-stuttgart.de (A.S.)

2 Aircraft Development and Systems Engineering (ADSE) BV, 2132 LR Hoofddorp, The Netherlands; evert.windels@adse.eu

3 Embraer Research and Technology Europe-Airholding S.A., 2615-315 Alverca do Ribatejo, Portugal; rjreis@embraer.fr

* Correspondence: eisenhut@ifb.uni-stuttgart.de

+ These authors contributed equally to this work.

check for updates

Citation: Eisenhut, D.; Moebs, N.; Windels, E.; Bergmann, D.; Geiß, I.; Reis, R.; Strohmayer, A. Aircraft Requirements for Sustainable Regional Aviation. Aerospace 2021, 8 , 61. https://doi.org/10.3390/ aerospace 8030061

Academic Editor: Ola Isaksson

Received: 11 December 2020

Accepted: 18 February 2021

Published: 26 February 2021

Publisher's Note: MDPI stays neutral with regard to jurisdictional claims in published maps and institutional affiliations.

\section{Copyright: (c) 2021 by the authors.} Licensee MDPI, Basel, Switzerland. This article is an open access article distributed under the terms and conditions of the Creative Commons Attribution (CC BY) license (https:// creativecommons.org/licenses/by/ $4.0 /)$.

\begin{abstract}
Recently, the new Green Deal policy initiative was presented by the European Union. The EU aims to achieve a sustainable future and be the first climate-neutral continent by 2050. It targets all of the continent's industries, meaning aviation must contribute to these changes as well. By employing a systems engineering approach, this high-level task can be split into different levels to get from the vision to the relevant system or product itself. Part of this iterative process involves the aircraft requirements, which make the goals more achievable on the system level and allow validation of whether the designed systems fulfill these requirements. Within this work, the top-level aircraft requirements (TLARs) for a hybrid-electric regional aircraft for up to 50 passengers are presented. Apart from performance requirements, other requirements, like environmental ones, are also included. To check whether these requirements are fulfilled, different reference missions were defined which challenge various extremes within the requirements. Furthermore, figures of merit are established, providing a way of validating and comparing different aircraft designs. The modular structure of these aircraft designs ensures the possibility of evaluating different architectures and adapting these figures if necessary. Moreover, different criteria can be accounted for, or their calculation methods or weighting can be changed.
\end{abstract}

Keywords: hybrid-electric propulsion; regional air travel; alternate airports; top-level aircraft requirements; figures of merit; aircraft design

\section{Introduction}

In the past, aviation has been a main driver for economic wealth by not only connecting millions of people, but also by providing a fast option for trade between different continents. Furthermore, it also enables tourism, which allows people to experience different countries and cultures to broaden their minds. This generates economic wealth for the destination region, which is especially valuable for developing countries with a remote tourism market [1]. Apart from the many benefits created by aviation, there are also downsides, primarily concerning environmental aspects. According to different studies, aviation is currently responsible for $1-2 \%$ of human-made $\mathrm{CO}_{2}$ emissions [1,2]. Aviation's impact on the environment is not only limited to $\mathrm{CO}_{2}$, but also includes other forms of emissions like $\mathrm{NO}_{X}$ or noise. While emitted greenhouse gases impact the climate and contribute to climate change [3], noise is expected to influence the health and general well-being of residents in the vicinity of airports [4]. Many efforts are being pursued by governments and the aviation sector itself to reduce negative impacts, with an ultimate goal of achieving sustainable aviation. 
In 2011, the European Commission presented the EU Aviation Sector's vision for the future of aviation, called Flightpath 2050 [5]. This report not only set goals for emission reductions, but also built a framework for the sector's market direction. Therefore, the vision pursued the aims of streamlining procedures and improving overall passenger experience. This included facilitating fast boarding, arriving at destinations on time regardless of weather conditions, and enabling $90 \%$ of European travelers to reach their destination from door to door within $4 \mathrm{~h}$. Apart from increasing the convenience of air travel for passengers, arriving on time and improving air traffic management also contribute to reducing emissions by causing fewer deviations and less otherwise "wasted" holding time and fuel.

Roughly eight years later, at the end of 2019, the European Union (EU) introduced the next step towards a sustainable future-the European Green Deal [6], which aimed to ensure that Europe would become the first "climate-neutral" continent on Earth. Similar to Flightpath 2050, the aims of this Green Deal included setting emission targets and enforcing a circular economy. These actions were not specifically aimed at aviation, but instead aimed to cover all of the sectors impacting the climate.

In addition to governmental policies, the aviation industry is also striving to become more sustainable in its own right. With the Carbon Offsetting and Reduction Scheme for International Aviation (CORSIA) initiative, the International Civil Aviation Organization (ICAO), as a subsidiary organization of the United Nations (UN), is also setting emission targets for the aviation industry. From 2021 onwards, carbon-neutral growth should be achieved, as well as an increase in energy efficiency by $2 \%$ per year until 2050 [2].

In addition, the UN in 2015 defined an agenda including 17 sustainable development goals and 169 targets to be achieved by 2030: "They are integrated and indivisible and balance the three dimensions of sustainable development: the economic, social and environmental" [7]. Moreover, the UN stated that a global effort is required to end poverty, respect human rights, create equality, and other essential goals, all while protecting the environment where "humanity lives in harmony with nature and [where] wildlife and other living species are protected" [7].

According to the Air Transport Action Group (ATAG) and their 2020 Aviation Benefits report [1], aviation plays a major role in supporting that agenda. To name just a few ways in which the aviation plays a main role: Before the COVID-19 pandemic, the aviation sector supported nearly 88 million jobs across the world, including direct, indirect, induced, and tourism related jobs. In addition, aviation supported $4.1 \%$ of the global gross domestic product [1].

Aviation has many benefits compared to other transport modes. The most important involves travel times, which are usually the lowest of all available modes of travel due to the straight flight paths that are possible without deviations being needed. Even in regional markets, this often holds true, despite the short distances that need to be covered to travel across these areas. This benefit is further increased if air travel is used to get across natural barriers like mountains, lakes, or the seas between islands. Air travel allows for connecting smaller cities to the already existing transport networks with lower infrastructure costs, thereby reducing development and maintenance spending. The only requirements to cover an airline route are airports at the departure and destination locations, each with sufficient infrastructure. No roads or rails are necessary in between these airports to facilitate air travel. Furthermore, more remote regions can be reached by air travel where a fast connection by other means of transport is not economically feasible or even where the route itself is not economically feasible at all.

According to an ATR market forecast, $58 \%$ of the worldwide regional air routes network was created between 2003 and 2018 [8]. To support this growth and add more remote regions to the global transport system in a sustainable way, the vision of a regional 50-passenger aircraft will allow for connecting smaller routes or simply destinations with reduced passenger and/or cargo volumes. To fulfill this purpose, it is expected that the size of the aircraft is reasonably defined. In addition, a smaller plane allows for more 
connections every day, if the demand is high enough, and reduces the risk of unprofitable flights due to low passenger volume at the same time. This will lead to more travel options for European citizens and a denser transport network interconnecting Europe. However, the higher number of connections must be cost efficient, and the aircraft must have competitive direct operating costs (DOCs) in comparison to other transport modes. In regional aviation, the impact of fuel consumption is amplified. As a result of the remoteness of most regional airports, the fuel transportation costs are increased. Compared to hub airports, the average fuel price at regional airports is higher by one third worldwide, and in some parts of Europe, even by a factor of two or more [8]. In addition, the transport further increases overall emissions.

Following the vision of the European Commission within Horizon 2020, an entry into service (EIS) for 2035/2040 for a hybrid-electric 50-seat regional aircraft seems challenging but feasible.

Electrifying the powertrain offers many benefits over conventional architectures. Electric motors provide power without any local emissions. The only emissions might result from producing the electric energy required to power the motors. Furthermore, electric motors scale almost linearly with regard to power and mass. This might enable the use of novel propulsion concepts like, for example, distributed (electric) propulsion, where efficiency can be increased, synergistically exploiting the interaction between the wing and propulsors.

Assuming green electric power, a fully electric aircraft would offer the lowest emissions during operations. For now, the range of such an aircraft would be limited due to the low specific energy of current battery technology. To tackle this flaw, a hybrid-electric concept combines the advantages of both worlds, i.e., the range provided by conventional fuel, and the emission reduction achieved by an electrified powertrain with higher efficiency. In addition, this concept enables new operation strategies where emissions can be managed based on different factors. In flight phases where the most harmful pollutions occur, using only the battery will allow for lower emissions of greenhouse gases and noise. Different hybrid-electric architectures offer further options for the design and operation of the aircraft. A parallel architecture allows for a power boost in high load scenarios like take-off or go-around. A serial architecture can increase redundancy or offers to replace a gas turbine with a battery pack as long as certification and technology requirements are met.

Apart from architectures and operation strategies related to local emissions, an additional degree of freedom is created by different energy management strategies. Having multiple energy/power sources allows for controlling the ageing of different powertrain components. With operating hours of a gas turbine building up, the battery could provide power originally produced by the turbine and vice versa. This will increase wear on the boosting component, but might help the operator to optimize the maintenance schedule.

In contrast to these benefits, the hybrid-electric system will add additional components to the aircraft which increase mass and complexity. The mass penalty has to be outweighed by a higher overall efficiency of the aircraft and other benefits. One is the required emission-free taxiing within Flightpath 2050, which can be fulfilled easily by the hybrid-electric aircraft (HEA). Furthermore, the added complexity will require a higher effort for certification. The HEA must achieve similar safety levels to a conventional aircraft. The different operating and energy management strategies might lead to additional redundancy. However, analyzing the overall architecture and different failure scenarios is challenging.

In this context, the project FUTPRINT50, which consists of 14 international partners, was formed. To address all these different challenges and to grasp the bigger picture, the project partners adapted a systems engineering approach [9] with a dedicated mission statement, which will be explained in the following paragraph. 
In Figure 1, the V-model of systems engineering is shown. It advises to break the overall design process into different levels and, by the iterative process, each level is revised whether expectations and requirements are fulfilled or not.

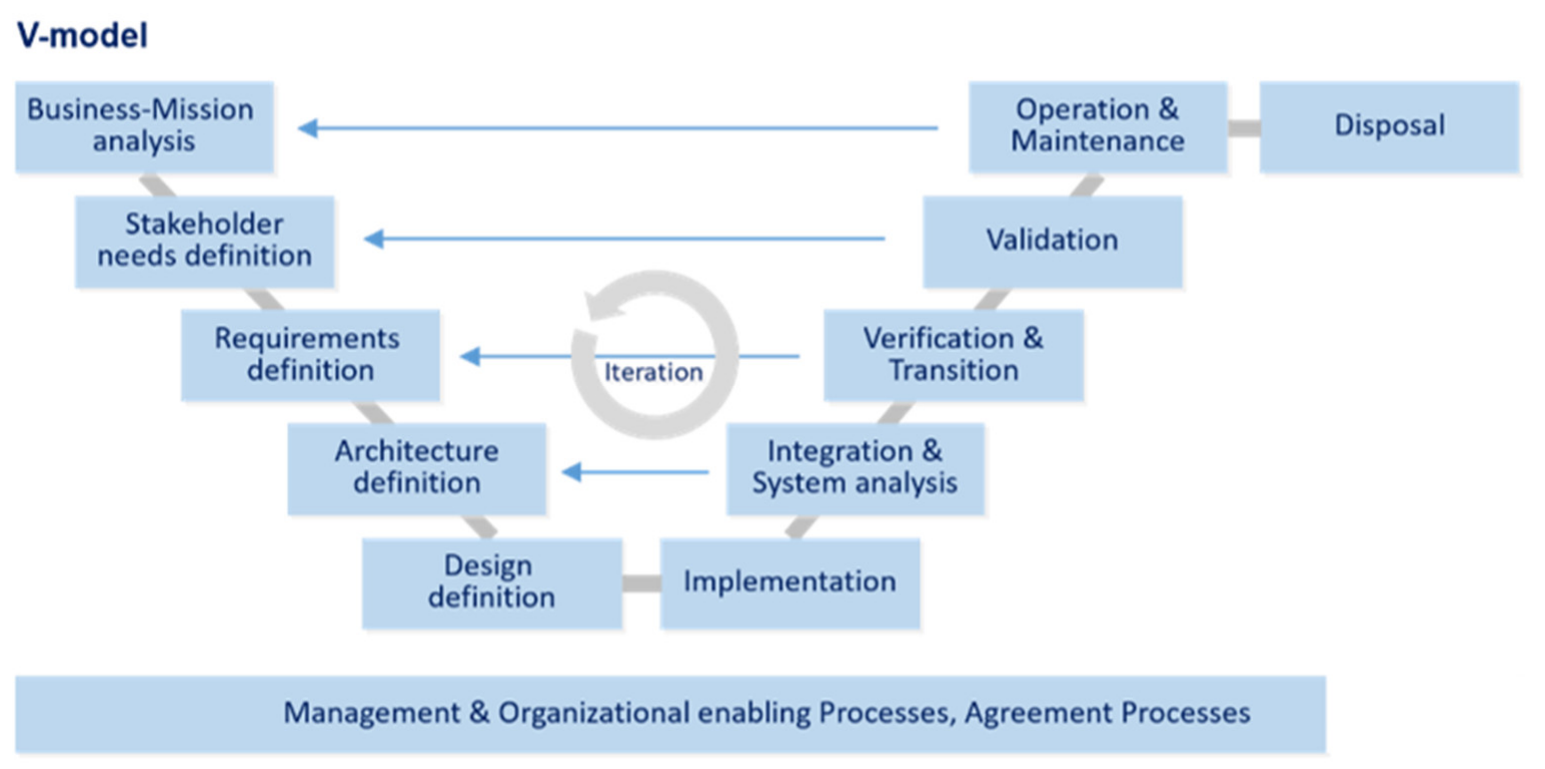

Figure 1. V-model of systems engineering.

The left part of the $\mathrm{V}$ starts with the need definition and works through to the definition of the design. The bottom side of the $\mathrm{V}$-model contains the actual design, including systems and sub-systems design. The right side starts with the implementation and integration. After this, the design will be tested and validated if all goals are achieved. Finally, actual operation will commence.

The first conceptual design is created by defining and implementing the systems at a higher level, i.e., general layout, propulsion type, disruptive technologies, etc. The starting point is defined by using existing data and a comparative aircraft analysis. The results create the basis for the top-level aircraft requirements (TLARs) and initial architecture and design definition. Consequently, the first concept is verified and validated, and a first concept of operations can be determined.

During the conceptual design phase, iterations are made to identify if the initial requirements are met, as is shown in the figure. At the end of the design, the entire conceptual product is evaluated to identify if it still satisfies the initial expectations. Requirements can be re-evaluated, and stakeholders can refine their needs, as one can learn from the first concept. This iteration is important when developing new disruptive designs and technologies, as one can never create the perfect starting point during the business and stakeholder analysis. Each overall iteration brings the design to a more detailed level, eventually converging to one final design, aligned with the stakeholders.

For the FUTPRINT50 project, the following stakeholders have been identified: EU citizen, authorities, operator, airport, air traffic management, supplier of energy, and the passenger. The stakeholders and their needs define the goals and requirements to make the project a success. Stakeholder interaction and analysis is required to define if the product or system to be designed fits in the overall picture. To better capture this overall picture, the product can be seen as a system within a system which is influenced by its surroundings (Figure 2a). 


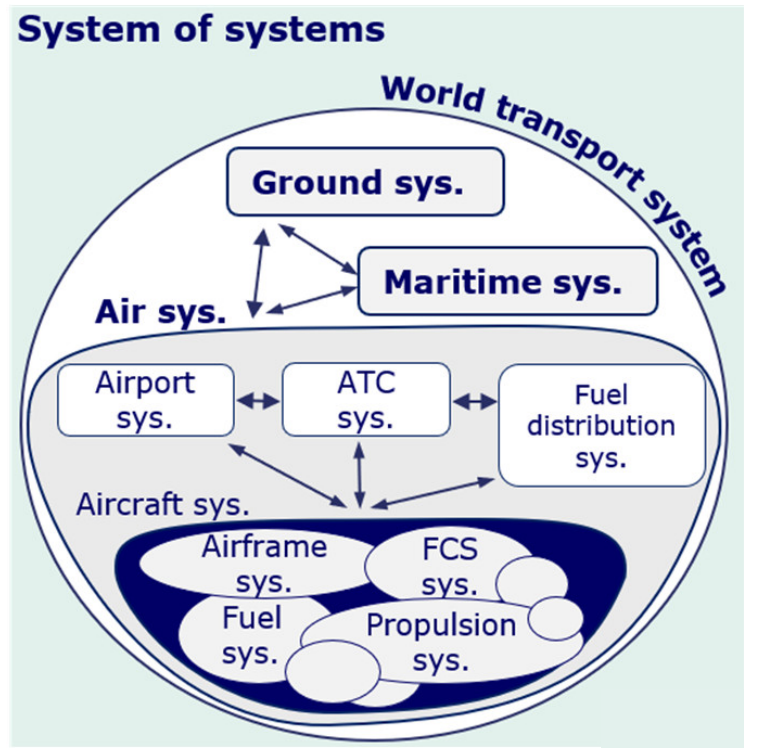

(a)

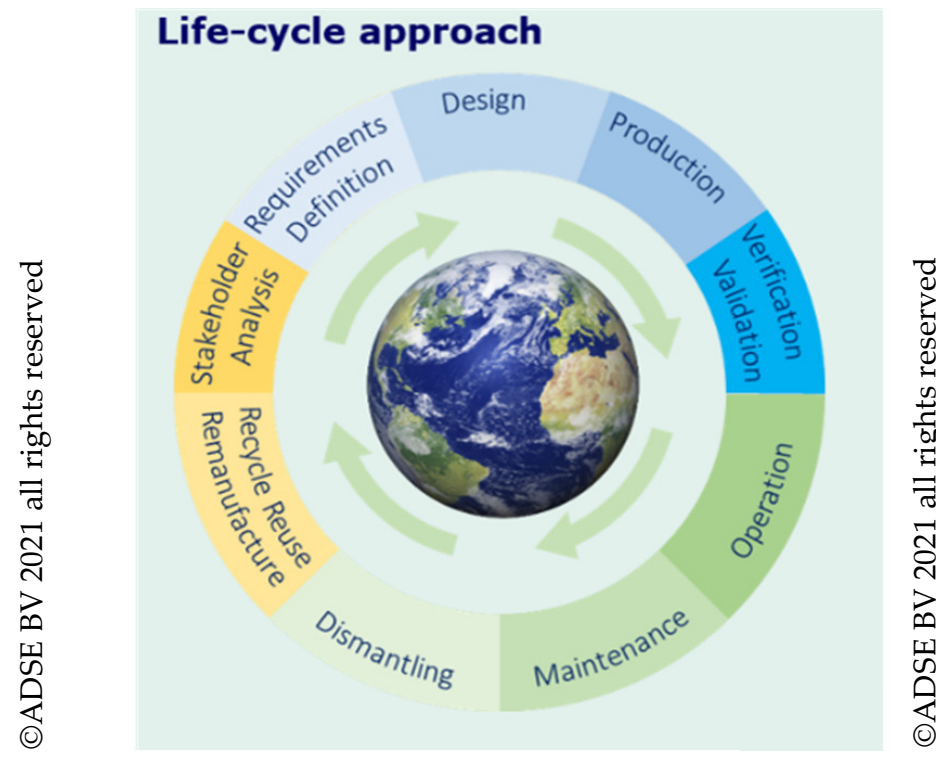

(b)

Figure 2. (a) System of systems and (b) life-cycle approach.

Taking this holistic view is important to grasp all aspects of the "larger" system and the stakeholders involved. The system of systems is one part of identifying the "larger" system, while another is the life-cycle approach shown in Figure 2b. Especially for sustainability, this shows that one should not only look at the operational period, but also all other sections of the life cycle to build a "green" solution. The needs and the requirements definition shall drive the design process to achieve a sustainable product in its life cycle, whilst still satisfying the stakeholders' needs within the systems of systems. The design decisions will drive emissions during all parts within the life cycle, which includes production, the operational phase, as well as end of life and recycling.

After formulating the needs and goals for the system, these could be summarized into a mission statement, used to define the system that is to be designed. The following is the current mission statement for a regional HEA:

"To develop a synergetic aircraft design for a commercial regional hybrid-electric aircraft up to 50 seats for entry into service by 2035/2040, to identify key enabling technologies and a roadmap for regulatory aspects. The clean sheet aircraft design shall help accelerate and integrate hybrid-electric aircraft and technologies to achieve a sustainable competitive aviation growth, as well as acting as a disruptor to regulators, air traffic management and energy suppliers."

The clean sheet aircraft design shall:

- have class-leading emissions and noise,

- include technologies that ensure (operational) safety,

- offer a competitive operational cost,

- $\quad$ offer operational improvements during exploitation compared to current regional aircraft,

- not enforce expensive changes to the current infrastructure.

This statement not only describes the system, but also highlights the benefits for the stakeholders. Within the V-model, it represents the first two levels, the business mission analysis and the stakeholder needs definition. These two provide the framework for the requirements definition represented by the TLARs.

The TLARs help to translate the abstract needs of the stakeholders to more manageable requirements on a system level. This includes specifications that should be precisely met, like the range, for example, or ones like emissions, where overachieving the goal is desirable. 
The V-model requires us to validate if the requirements are fulfilled by the design. Therefore, figures of merit have been defined in the process and are shown in Section 4. They not only check if the requirements are fulfilled, but also add the possibility to compare different design approaches and to identify superior concepts. This is especially necessary for complex interwoven requirements like emissions and DOCs. On the one hand, capital cost as part of the DOCs might increase due to the higher development and manufacturing cost of a more environmentally friendly airplane. On the other hand, when emissions are taxed, this might increase the DOCs for aircraft with higher emissions.

\section{Top-Level Aircraft Requirements}

All defined TLARs are grouped in different categories, relating to environment, market, operations, performance, and regulations [9]. This helps to evaluate the design with respect to different aspects. All requirements within these categories and their reasoning are explained in the following sections. It is important to note that these requirements are the result of a comparative aircraft analysis, evaluated for our hybrid-electric configuration. The purpose is to capture the requirements for an aircraft that has comparable or better characteristics than the current state-of-the-art, considering potential limitations regarding a realistic timeline for technology readiness.

\subsection{Environment}

The environmental requirements are mainly derived from Flightpath 2050, and all adopted requirements are shown in Table 1 . Defined emission reductions for $\mathrm{CO}_{2}, \mathrm{NO}_{\mathrm{X}}$, and noise are directly implemented into our TLARs.

Table 1. Top-level aircraft requirements (TLARs) with regard to environmental aspects.

\begin{tabular}{cc}
\hline TLAR (Environment) & Value \\
\hline Reduction of $\mathrm{CO}_{2}$ emissions & $\geq 75 \%$ vs. ATR-42 \\
Reduction of $\mathrm{NO}_{X}$ emissions & $\geq 90 \%$ vs. ATR-42 \\
Reduction of Noise emissions & $\geq 65 \%$ vs. ATR-42 \\
Emissions during ground operations & No emissions of $\mathrm{CO}_{2}$ and $\mathrm{NO}_{X}$ \\
Materials used in the design & Sustainable end of life solution \\
Use of alternative propellants & Yes \\
\hline
\end{tabular}

In addition to the emissions reduction during flight, all ground operations should be performed emission-free, including taxiing. In general, there are two options available: Either an emission-free system is integrated into the aircraft, or the aircraft is towed by an electric truck on the ground. The first option is easily fulfilled by the HEA. In comparison, a conventional aircraft would require a system solely for the purpose of emission-free taxiing. During all other mission sections, this system is dead mass that penalizes the overall aircraft performance. The second option, an electric tow truck, requires infrastructure on the ground at every serviced airport. Especially for smaller regional airports, this might limit the profitability of either the aerodrome itself or the desired connection.

Furthermore, the goal is not only to reduce overall emissions during the operational phase, but also during the whole aircraft life cycle. Therefore, the materials used should allow a sustainable solution like recycling or reusing at the end of life. This connects to the life-cycle approach described earlier.

The final criterion is the usage of alternative propellants. This is not only limited to drop-in sustainable aviation fuels (SAF) that replaces conventional jet fuel, but also specifically allows for hydrogen.

These defined environmental requirements would not only incorporate the Flightpath 2050 goals, it would also account for further political initiatives, like the European Green Deal [6] and its aim of being climate neutral in 2050. This can be achieved by SAF or green hydrogen in combination with a life-cycle approach that also considers recyclability in a 
circular economy. In this case, there is only a minor difference for aviation between the Flightpath 2050 goals and the Green Deal.

\subsection{Market}

Table 2 shows all aspects related to market requirements, including operator demand and passenger comfort. Aiming at the regional air traffic market, the number of passengers is set to 50 .

Table 2. Top-level aircraft requirements with regard to market.

\begin{tabular}{cc}
\hline TLAR (Market) & Value \\
\hline Number of passengers & $\leq 50$ \\
Cargo capacity & $\geq 500 \mathrm{~kg}$ \\
Luggage bins & $\geq 0.06 \mathrm{~m}^{3} /$ passenger \\
In-flight entertainment & Seamless connectivity \\
Cabin altitude & $\leq 2000 \mathrm{~m}(6560 \mathrm{ft})$ \\
Cabin ventilation & $\geq 0.25 \mathrm{~kg} / \mathrm{min}$ fresh air per passenger \\
Cabin temperature & $2{ }^{\circ} \mathrm{C}$ \\
Cabin humidity & $10 \%$ \\
Lavatory & $\geq 1$ \\
Galley & $\geq 1$ \\
Direct operating costs & $\geq 98 \%$ \\
Dispatch reliability & Competitive with ground transport \\
\hline
\end{tabular}

As the world is coming closer together, not only fast connections for passengers are required, but also for cargo. Therefore, the cargo capacity is set to at least $500 \mathrm{~kg}$ if maximum passengers are on board. In addition, it should be possible to quickly convert the plane from passenger to cargo and vice versa. Furthermore, a combi-version would allow for trading some passengers for additional cargo. This allows flexibility for the operators and gives them the ability to react to different needs in different markets/regions.

In regional aviation, mostly carry-on luggage is used. This also helps with the turnaround time defined in the previous section. To allow for enough space in the cabin, the luggage bins are sized that each passenger has $60 \mathrm{~L}$ available. This is comparable to the current Embraer E-Jet E1 family, which is larger than the bin size of current turboprop aircraft, for improved traveler experience. Furthermore, the volume of regular hand luggage $(55 \mathrm{~cm} \times 40 \mathrm{~cm} \times 20 \mathrm{~cm})$ is only $44 \mathrm{~L}$.

No conventional in-flight entertainment will be integrated, but seamless connectivity like Wi-Fi should be provided. The flight duration is rather short, and connection to the internet is expected to be more essential, especially for business trips where the passenger is able to work during the flight. To share flight information, an app could be provided for example.

Cabin pressure is set to $2000 \mathrm{~m}(6560 \mathrm{ft})$, which complies with certification specifications (CS) that require a cabin pressure altitude of less than $2438 \mathrm{~m}$ (8000 ft) (CS 25.841 (a)) [10]. For the short flight time of the regional aircraft, a lower altitude is not needed. New airplanes for long routes like the Airbus A350 and the Boeing 787 are already using a cabin altitude of $6000 \mathrm{ft}$, so the trend and market requirements for regional aviation have to be closely monitored.

To comply with CS-25, cabin ventilation must be designed to provide every passenger with at least $0.25 \mathrm{~kg}$ of fresh air per minute. The exact required ventilation capacity is closely connected to the temperature and humidity requirements. Every passenger on board generates heat and moisture. To keep the temperature at $23{ }^{\circ} \mathrm{C}$ and humidity at $10 \%$, the air inside the cabin must be reconditioned, which in the end defines the exchange rate for cabin ventilation.

For passenger comfort, at least one lavatory has to be installed. Despite the trend going to serve less warm food on-board, at least one galley is foreseen. This ensures the possibility to offer hot beverages like coffee or tea during flight. 
As already described, the goal of the aircraft is not to replace other transport modes. Therefore, the DOCs should be competitive with public ground transport. A metric for comparison might be the expected ticket price for each transport. Furthermore, a comparison to car travel might be of interest, even more so as the majority of cars is expected to be electric by 2040. Another important aspect which drives the DOCs of the airplane is the dispatch reliability, which should exceed $98 \%$. This will increase utilization of the airplane for the operator and thus the potential profit.

\subsection{Operations}

To ensure operational flexibility for an aircraft capable of servicing many airports and achieving high utilization, operational aspects have to be considered as top-level requirements (see Table 3).

Table 3. Top-level aircraft requirements with regard to operational aspects.

\begin{tabular}{cc}
\hline TLAR (Operations) & Value \\
\hline Wingspan & $<36 \mathrm{~m}$ \\
Weather operations & All weather \\
Turn-around time & $\leq 25 \mathrm{~min}$ \\
\hline
\end{tabular}

ICAO Annex 14 [11] defines categories by which an aerodrome is rated. The number is related to the reference field length and the letter is based on the wingspan of the airplane. For the HEA, a category $2 \mathrm{C}$ aerodrome is required by the TLAR definitions. The "lower" the category, the more airports are available to be serviced by the aircraft. The letter $\mathrm{C}$ refers to the maximum wingspan of less than $36 \mathrm{~m}$. This is similar to the ATR 42, which has a wingspan of just more than $24 \mathrm{~m}$. A lower airport category seems to be unfeasible, as the limit for category B is $24 \mathrm{~m}$. Future aircraft will likely have higher aspect ratios than the ATR 42, with an expected higher maximum take-off mass (MTOM) for an HEA, and also the wing area will be increased to end up with a similar wing loading. In combination overall, an increase in wing span is expected.

Another aspect of particular interest with respect to utilization is the weather conditions the aircraft is capable of operating in. As the goal is to design an aircraft for commercial operations, the general dispatchability should be high. Therefore, obviously the aircraft must be capable of operating in all weather conditions including icing, for example.

To further increase productivity, a turn-around time of no more than 25 min should be obtained. This is comparable to current regional aircraft like the EMB-145 or the De Havilland DHC-8-300 [12,13].

\subsection{Performance}

In Table 4, the TLARs with regard to performance are given. Because range and reserve policy are crucial aspects, they are analyzed separately in more detail.

The design cruise speed is set to $450-550 \mathrm{~km} / \mathrm{h}$, which is comparable to current turboprops. Reducing this speed would harm productivity of the aircraft by affecting the number of dispatches per day. Increasing it will raise the number of dispatches, but more excess thrust or power is required to accelerate the aircraft. Therefore, the aircraft mass might increase which limits the benefits gained. The design payload of $5300 \mathrm{~kg}$ is calculated by the number of passengers multiplied with their mass including luggage, which is estimated to be $106 \mathrm{~kg}$. The maximum payload of $5800 \mathrm{~kg}$ is defined by the design payload plus $500 \mathrm{~kg}$ of cargo mass. 
Table 4. Top-level aircraft requirements with regard to performance.

\begin{tabular}{|c|c|}
\hline TLAR (Performance) & Value \\
\hline Design cruise speed & $450-550 \mathrm{~km} / \mathrm{h}$ (Mach $0.40-0.48)$ \\
\hline Design payload & $5300 \mathrm{~kg}$ \\
\hline Maximum payload & $5800 \mathrm{~kg}$ \\
\hline Design range (design cruise speed, design payload) & $400 \mathrm{~km}+$ reserve \\
\hline Maximum range (design cruise speed, design payload) & $800 \mathrm{~km}+$ reserve \\
\hline Reserve fuel policy & $185 \mathrm{~km}+30 \mathrm{~min}$ holding \\
\hline $\begin{array}{l}\text { Range from hot and high airports (design payload, international standard } \\
\text { atmosphere (ISA) }+28,5400 \mathrm{ft} \text { ) }\end{array}$ & $450 \mathrm{~km}+$ reserve \\
\hline Range from cold airports (design payload, ISA -30) & $450 \mathrm{~km}+$ reserve \\
\hline Take-off field length (maximum take-off mass (MTOM), sea level (SL), ISA, paved) & $\leq 1000 \mathrm{~m}$ \\
\hline Take-off field length STOL (SL, ISA, paved, $>80 \%$ pax) & $\leq 800 \mathrm{~m}$ \\
\hline Landing field length (SL, ISA, paved) & $\leq 1000 \mathrm{~m}$ \\
\hline Rate of climb (MTOM, SL, ISA) & $\geq \overline{1850 \mathrm{ft} / \mathrm{min}}$ \\
\hline Rate of Climb at top of climb & $\geq 1.5 \mathrm{~m} / \mathrm{s}(300 \mathrm{ft} / \mathrm{min})$ \\
\hline Time to climb to FL 170 & $\leq 12.7 \mathrm{~min}$ \\
\hline Maximum operating altitude & $7620 \mathrm{~m}(25,000 \mathrm{ft})$ \\
\hline Service ceiling for one engine inoperative (OEI) (or equivalent) (95\% MTOM, ISA +10) & $4000 \mathrm{~m}(13,125 \mathrm{ft})$ \\
\hline
\end{tabular}

The take-off field length (TOFL) is characterized by two values. The first one is for standard operation with full capacity, and here the TOFL is defined as $1000 \mathrm{~m}$. The second one is defined for short take-off and landing (STOL) to allow access to smaller airportshere a TOFL of $800 \mathrm{~m}$ is required for a passenger load factor of more than $80 \%$ compared to full capacity. The exact achievable load factor for this requirement will be a result of the final design and the grade of optimization for standard operations. Additionally, both field lengths are the criterion for landing as well. This means that for the two different kinds of operations, the landing field lengths must be no greater than $1000 \mathrm{~m}$ and $800 \mathrm{~m}$, respectively.

All these field lengths depend on the maximum lift coefficient, where a "certifiable" coefficient should be reached. "Certifiable" describes that, for example, in case of high-lift distributed propulsion, the aircraft must still reach an acceptable sink rate in descent. If the thrust generated for the required lift would exceed the drag of the configuration, the aircraft would climb instead of losing altitude. In this case, energy harvesting could be beneficial for the overall aircraft. In general, if a novel high-lift system is used, it has to have equivalent safety compared to current conventional technology in all possible conditions, e.g., crosswinds. To address this, the National Aeronautics and Space Administration carried out initial analyses for the Maxwell X-57 and made suggestions for the design of high-lift distributed propellers [14].

The minimum rate of climb at MTOM in international standard atmosphere (ISA) conditions at sea level (SL) is set to $1850 \mathrm{ft} / \mathrm{min}$, which is comparable to the ATR 42 today [15]. This ensures operational capabilities and allows the operators to service equivalent routes than current turboprop aircraft.

For the rate of climb at the top of climb, $1.5 \mathrm{~m} / \mathrm{s}$ or $300 \mathrm{ft} / \mathrm{min}$ is defined. This ensures the aircraft's ability to perform maneuvers to avoid collisions when cruising at the top of climb. This value might change in the future if airspace rule dynamics change.

The overall climb performance is defined by the time to climb to FL 170. This criterion makes the climb comparable to other aircraft (ATR 42-600: $12.7 \mathrm{~min}$ [15]) because power, and therefore the rate of climb, depends on altitude for air-breathing propulsion. In hybrid-electric aircraft, these losses could be countered by the battery.

A maximum operating altitude FL 250 or $7620 \mathrm{~m}$ is defined for a few reasons. Firstly, above that altitude, a redundant air management system is required (CS 25.841) [10]. This would result in a higher system complexity and an increase in total aircraft mass. Secondly, due to the typical turboprop mission duration of one hour, a higher cruise altitude is often not required, as it will result in a longer climb segment. This will not only require more power, but also more fuel, which might not be offset by a more efficient cruise in higher 
altitude. Furthermore, the passenger comfort is increased when the cruise segment takes up a significant portion of the overall flight. Lastly, it is expected that the formation of aviation induced clouds and contrails at that defined altitude, and thus the climate impact of the aircraft is significantly lower [16].

The service ceiling with one engine inoperative (OEI) is set to $4000 \mathrm{~m}$, or $13,125 \mathrm{ft}$, to overfly mountain ranges in most regions of interest to air traffic and is comparable to current turboprops [15]. This criterion is set for $95 \%$ of MTOM and ISA +10. For the HEA, the term OEI must be adapted in relation to the selected power train architecture and propulsor configuration.

\subsubsection{Range}

The design range of the regional aircraft is a major point concerning its future mission and purpose. The aim of regional air travel is a closer connection of rural areas and to realize a fast connection between cities. This is connected to the Flightpath 2050 goal that " $90 \%$ of travellers within Europe are able to complete their journey, door-to-door within 4 hours" [5].

The regional flights should enable an easy and fast way to also travel on routes with lower passenger volume, similar to remote bus and train connections. Thereby traveling by air should work in synergy with other modes of transportation, enabling routes which are difficult or not cost-effective to realize with ground-based transport systems or add a significant and useful time differential.

At first, the coverage of airports in the EU plus Great Britain, Norway, and Switzerland is analyzed (see Figure 3). This leads to a number of 414 airports with a field length of more than $1000 \mathrm{~m}$ (430 airports for $800 \mathrm{~m}$, respectively) that have a volume of more than 15,000 passengers per year according to the data of the reported airports by Eurostat in 2019 [17], excluding overseas departments. It is expected that these airports are commercially in use. Under the assumption of a $100 \mathrm{~km}$ catchment area around the airports, major parts of the EU are already covered. We expect that a larger catchment area does not result in any advantages for the traveler, since no time advantage is expected. Furthermore, we assumed that no emission savings can be achieved for a catchment area of more than $100 \mathrm{~km}$.

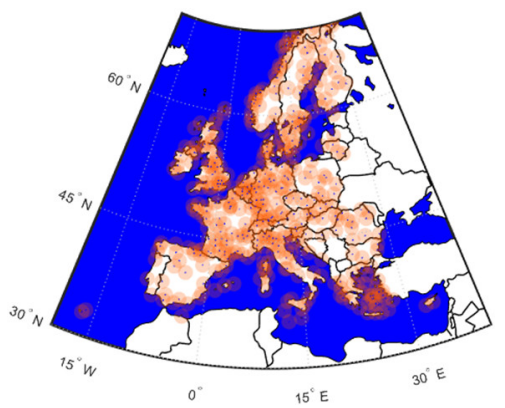

(a)

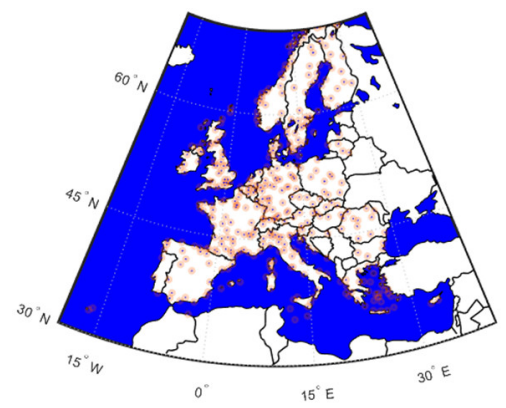

(b)

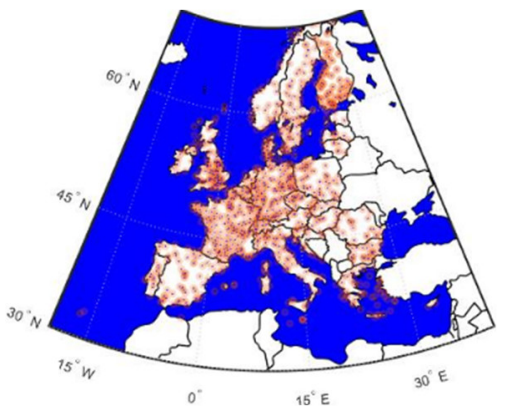

(c)

Figure 3. Coverage area of European commercial airports with an assumed catchment radius of (a) $100 \mathrm{~km}$, (b) $50 \mathrm{~km}$, and (c) $50 \mathrm{~km}$ considering all airfields of at least $1000 \mathrm{~m}$ runway.

For regions with low transport infrastructure (no highway, no railway, mountainous regions) the catchment area has to be adjusted because of a slower travel speed. Here, a more suitable radius of the catchment area for regional air traffic would be $50 \mathrm{~km}$ or even less from an airport. Considering this smaller catchment area, there is only sufficient coverage for metropolitan areas. These urban areas are often already connected to the regional traffic network. However, air travel can realize new and faster connections between these areas as an alternative means of transport.

However, if we consider airports or airfields in general (commercial or not) with a runway (concrete and asphalt) of at least $1000 \mathrm{~m}$, a higher degree of coverage can be achieved. A study based on EU airports provided in the database of OpenAIP [18] has 
shown that 1112 airports and airfields fulfill this requirement (the study also includes military airfields). Taking these airfields into account, nearly all regions of the EU can be connected to a regional air traffic network. Assuming that these regions are often barely connected to a fast transport infrastructure network, this will greatly contribute to the European vision presented in Flightpath 2050.

To allow regional travel in the EU with an aircraft in respect to the defined goals of Flightpath 2050, as well as worldwide defined climate objectives, the design range is set to $400 \mathrm{~km}$ and the maximum range to $800 \mathrm{~km}$, respectively. It is assumed that for this range, it is possible to develop an aircraft with EIS 2035/2040 reaching the global climate goals and to enable a regional air transportation system as an extension of the current traffic infrastructure. To connect different regions and cities in the EU, the existing commercial airports with a field length of $1000 \mathrm{~m}$ or more in operation already enable 12,467 routes (distance between $350-800 \mathrm{~km}$ ). For a field length of $800 \mathrm{~m}$ or more, this would result in 13,214 routes. In both cases, these connections of interest to regional flight cover approximately $15 \%$ of the flight connections in the EU with a distance of more than $250 \mathrm{~km}$ (Figure 4).

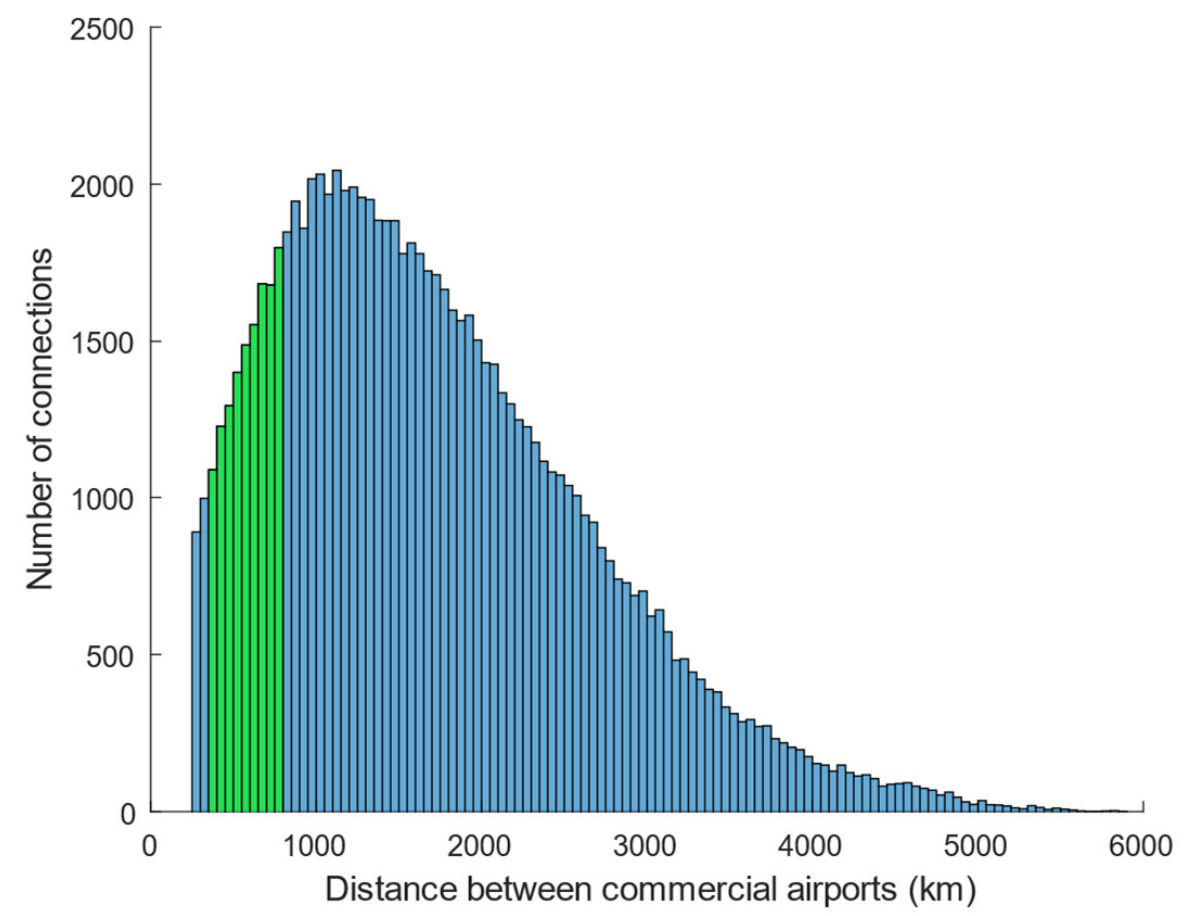

Figure 4. Number and distance of flight connections in the EU (plus Great Britain, Norway, and Switzerland) concerning commercial airports in operation (blue + green) - feasible connections for regional air traffic (green). All connections of more than $6000 \mathrm{~km}$ are not displayed.

Due to the lower passenger capacity of the planned aircraft, less populated regions could also be connected to the EU traffic network even if there is a lower passenger and cargo volume demand. The availability of these air connections has been shown to play a role regarding regional development [19]. Figure 5 shows the coverage of different ranges for existing commercial airports with a field length of at least $1000 \mathrm{~m}$. It can be seen that nearly all states of the EU can be covered, excluding some islands and overseas departments. 


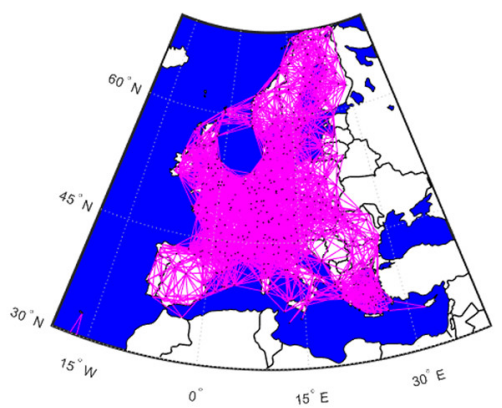

(a)

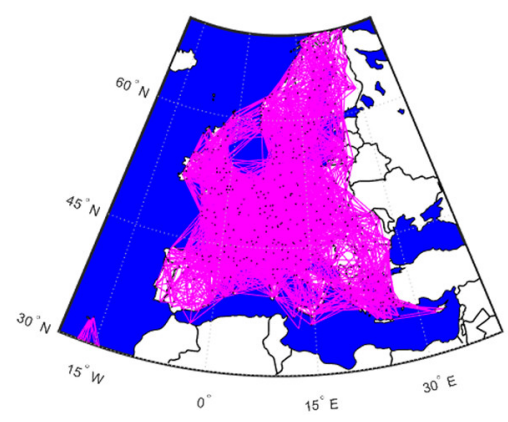

(b)

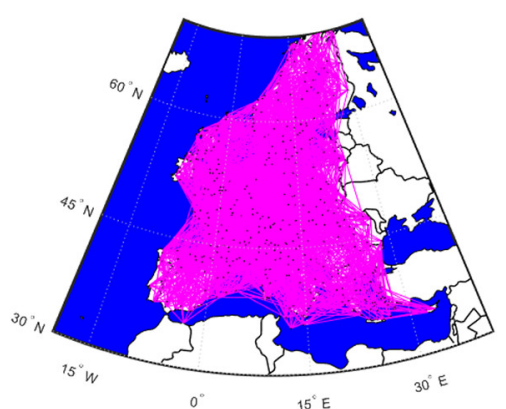

(c)

Figure 5. Connections between commercial airports in operation in different distances (a) $350-500 \mathrm{~km}$, (b) 500-650 km, and (c) $650-800 \mathrm{~km}$.

The two examples in Figure 6 showcase possibilities within this regional air traffic system. The first is Strasbourg, France, in the heart of the EU and the seat of the European Parliament. Only considering a distance between $350-800 \mathrm{~km}, 113$ connections can be realized. The figure on the right presents domestic air traffic between the Greek mainland and islands. This could be an addition to current ferry connections for faster travel between the islands with a bigger distance. Therefore, the minimum flight distance was reduced to $150 \mathrm{~km}$.

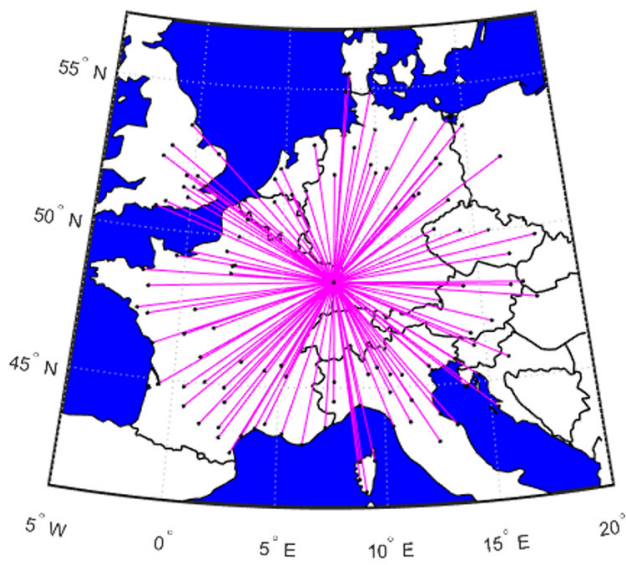

(a)

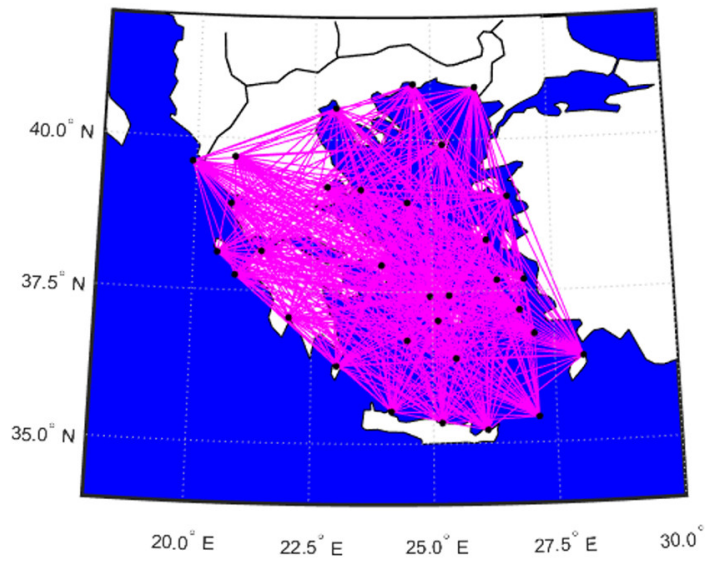

(b)

Figure 6. Example (a) Connections from Strasbourg (SXB) between 350-800 km, Example (b) Feasible domestic flight routes of Greece between $150-800 \mathrm{~km}$.

\subsubsection{Reserve Policy}

Within ICAO Annex 6 [20], topics concerning the operation of aircraft are covered. This includes fuel requirements for a safe execution of a complete flight. It defines that the minimum amount of usable fuel should account for the following parts: Fuel required for taxiing and the overall trip, including a contingency fuel for unforeseen factors. The reserves are split into fuel required to reach the alternate airport and a final fuel reserve, which for a turbine driven aircraft is set to $30 \mathrm{~min}$ of holding at holding speed, $1500 \mathrm{ft}$ above ground level.

The distance to the alternate, and therefore required, fuel is specific to the planned route. For this project, it is defined as $185 \mathrm{~km}$ in general, which is equal to about $23 \%$ of the maximum range. In many regions, this is expected to be enough for most regional flights. Two main events can happen that require diverting to an alternate. First, having already reached the planned destination and being required to divert to another airport, for example, because the airport was closed due to an accident. Second, being en route and the weather at the planned destination worsens, requiring the flight to divert to an en route alternate. 
For the first case, having already reached the destination and being required to divert, Figure 7 shows the number of potential alternates for airports in the EU (including Great Britain, Norway, and Switzerland). Out of the 414 commercially operated airports with a field length above $1000 \mathrm{~m}, 3$ have no alternate within the defined reserve distance. This yields more than $99 \%$ of airports adequately covered. Over $90 \%$ have more than one alternate within reach. To correctly define airports with missing alternates, airports in Serbia, Bosnia, and Herzegovina, Montenegro, Kosovo, Albania, North Macedonia, Belarus, and Ukraine were added in all reserve analysis. Here, the same criteria for the airport selection have been applied (field length of at least $1000 \mathrm{~m}$ and yearly passenger volume of at least 15,000).

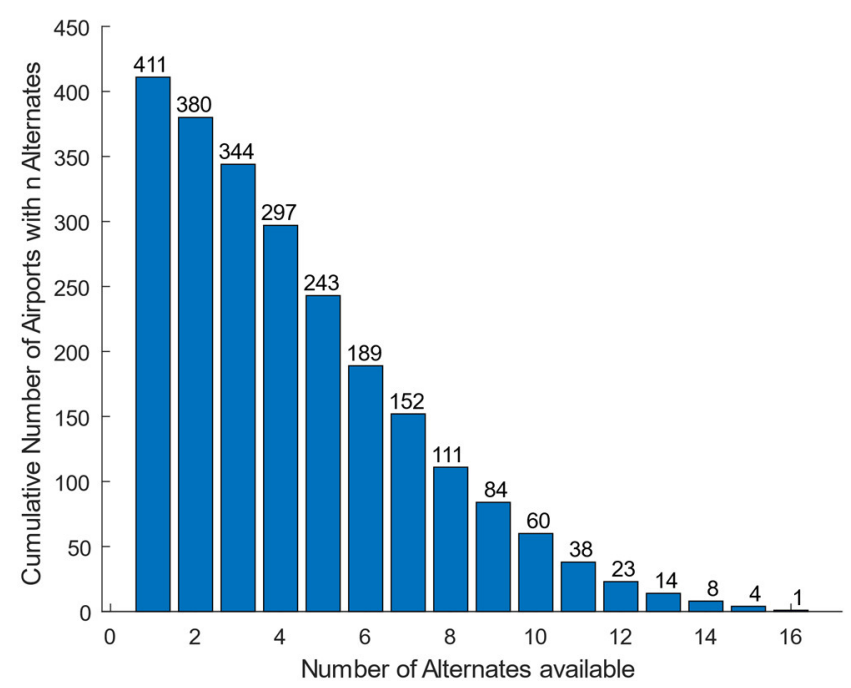

Figure 7. Cumulative number of airports that have $n$ available alternates within reach by the defined reserve distance.

The three airports not included are highlighted in Figure 8, with a circle representing the defined reserve distance. We can see that the airports of Lisbon (LIS) in Portugal, Flores (FLW) on the Azores, and Longyearbyen (LYR) on Svalbard lack an adequate alternate airport.

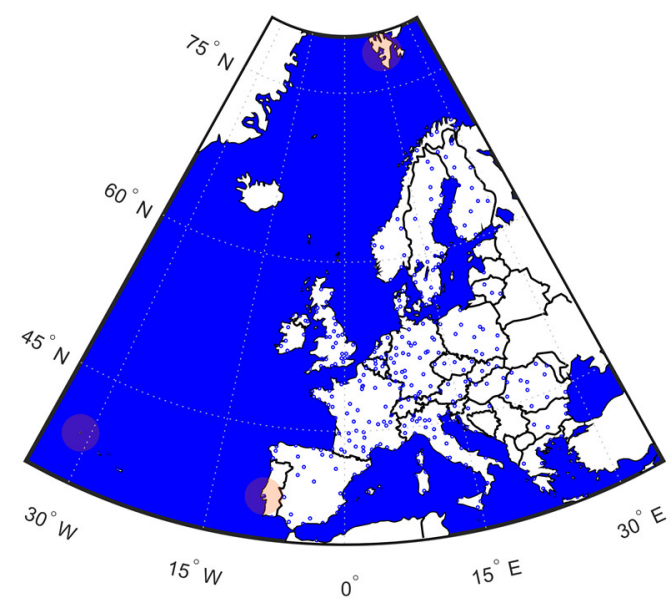

Figure 8. Airports that have no alternate in reach with the specification given in the TLARs.

The farthest distance to an available alternate is $945 \mathrm{~km}$ for Longyearbyen, which is longer than the maximum range of the aircraft; therefore, the airport is not relevant for the analysis. This leaves a number of 413 airports investigated in total. For the other two airports, the distance to an alternate equals $234 \mathrm{~km}$ for Flores and $201 \mathrm{~km}$ for Lisbon. 
To better account for operational aspects, two safety factors are introduced for a second study. First, a safety margin should be applied in order to derive from the theoretical range of the great circle to a practical range. For this, a distance increase by $5 \%$ was assumed. Second, a safety factor should consider adverse headwind conditions, which increase the energy required to reach the diversion airport. If a "fresh breeze" on the Beaufort Scale is assumed as the reference value with wind speeds up to $38 \mathrm{~km} / \mathrm{h}$, the flight time of an aircraft with a cruise speed of $550 \mathrm{~km} / \mathrm{h}$ would be increased by around $7 \%$, and consequently the required energy for the flight is increased accordingly.

Figure 9 shows that by including safety factors, the number of airports without any alternate within reach is increased by ten. With 3\%, the fraction of airports with no alternate is still small. For these twelve airports, the distances required vary between slightly over $185 \mathrm{~km}$ up to $263 \mathrm{~km}$, again with Flores on top. This shows that even with unfavorable conditions, the selected reserve policy is suitable for the vast majority of airports in Europe.

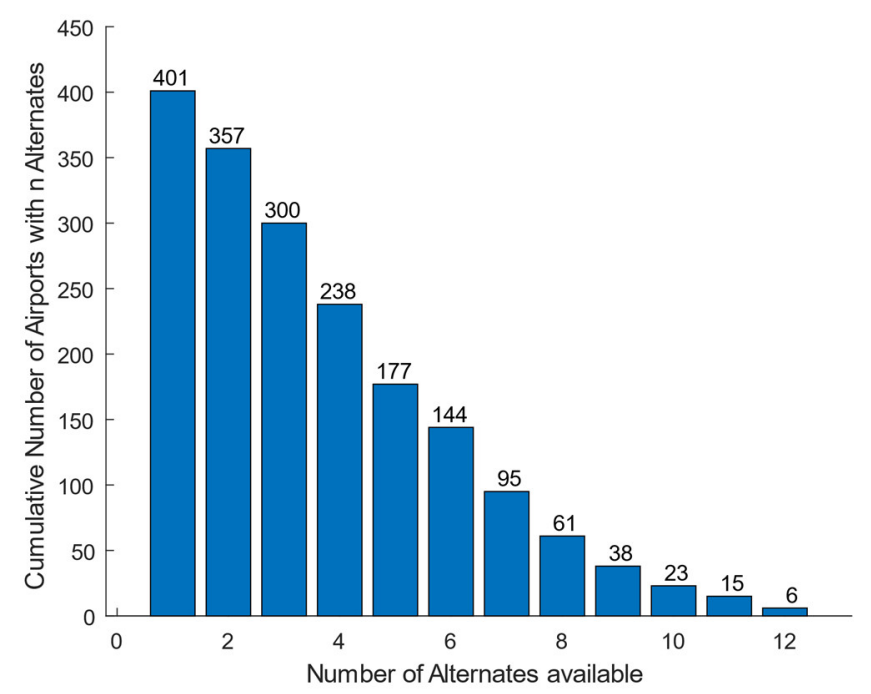

Figure 9. Cumulative number of airports that have $n$ available alternates within reach by the defined reserve distance including safety factors for practical range and adverse headwind.

It must be mentioned that some airports do have potential alternates within the defined range without being recognized in this calculation. That is because they do not meet the requirements previously set, e.g., within Lisbon's range, Beja airport (BYJ) is not serviced by any regular scheduled flights at the moment and has a yearly passenger volume of less than 15,000 passengers.

For the second case, the distance to an en route alternate is expected to be lower than it is after having already reached the planned destination. Even when the distance to an alternate en route is higher than the defined reserve distance, the aircraft still has the energy for the remaining trip, which then could be used to reach an alternate. In case of an HEA with different energy sources like fuel and batteries, this might require that there is no single point of failure within one system part. Otherwise, if only one combustion engine and generator are installed and one component fails, the battery might not be able to provide the required energy to reach any airport.

In order to determine the distance to the nearest suitable en route alternate airport, a mesh of possible aircraft positions over land was created, expressed in latitude $\phi$ and longitude $\lambda$. Aircraft positions over sea and islands, except for Great Britain and Ireland, were excluded at this stage. The mesh applied in the calculation consists of positions with a spacing of $1 / 60^{\circ}$ in latitude $\left.\Delta\right] \phi$ and longitude $\Delta \lambda$, which corresponds to a maximum spacing of approximately 1 nautical mile. In Figure 10, an exemplary mesh is shown with a spacing of $1^{\circ}$ in latitude and longitude. Consequently, the shortest distance of each aircraft position to the suitable en route alternate airports is determined by calculating the length 
of the great circle to each individual airport and determining the minimum value. With the data obtained, a cumulative frequency plot was created.

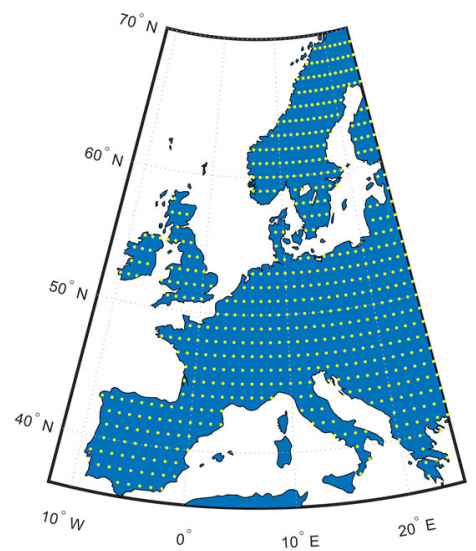

Figure 10. Exemplary visualization of investigated aircraft positions in Europe with a spacing of $1^{\circ}$ in latitude and longitude - the calculation was carried out with a spacing of $1 / 60^{\circ}$, which results in a maximum spacing of approximately $1 \mathrm{NM}$.

Figure 11 shows the database of alternate airports on the left and the resulting curve for airports within the investigated parts of Europe featuring a concrete or asphalt runway with a field length of more than $1000 \mathrm{~m}$ on the right. Suitable diversion airports from $95 \%$ of all investigated aircraft positions can be reached within $120 \mathrm{~km}$. A percentage of $99 \%$ can be reached within $148 \mathrm{~km}$, and the farthest distance is $198 \mathrm{~km}$ southeast of Madrid $\left(38.8^{\circ} \mathrm{N}, 2.75^{\circ} \mathrm{W}\right)$.

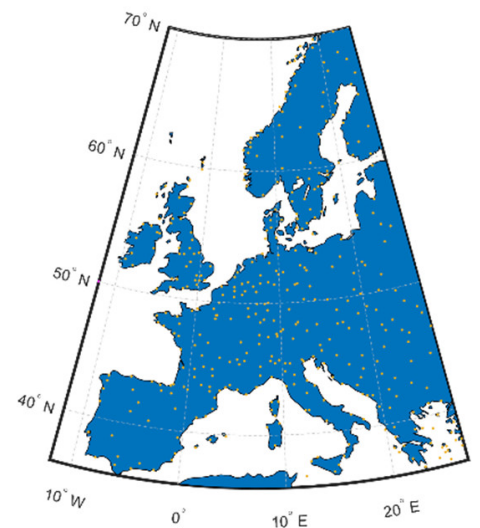

(a)

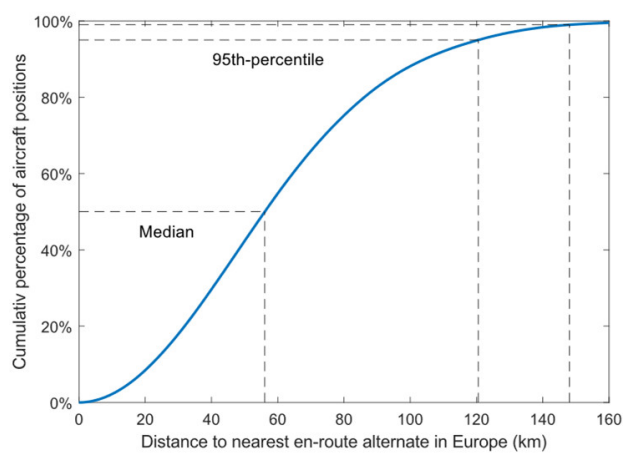

(b)

Figure 11. Possible alternate airports (a) and plot of cumulative frequency of the distance to a suitable en route alternate with a concrete or asphalt runway $(\mathbf{b})$.

The maximum error of the calculation is evaluated by considering the distance of a possible aircraft position, which is located exactly in between the mesh of evaluated aircraft positions and can be determined to be $1.26 \mathrm{~km}$ [21]. For this evaluation, similarly to the first analysis, safety factors for deviations from the great circle and headwind conditions could be applied.

\subsection{Regulatory Aspects}

In general, this type of aircraft has to comply with CS-25. So, all requirements from this CS have to be fulfilled. An HEA is not fully certifiable under the current regulations in place. Some gaps have already been identified. For example, a battery could be used as redundancy within a serial architecture, and therefore one gas turbine might be enough for a safe design. 
Looking at novel propulsion concepts like distributed propulsion, a new definition of the OEI condition is needed. Not limited to distributed propulsion, the overall propulsion architecture will need analysis. Depending on the interdependencies of different systems and their redundancies, a similar definition might emerge. Due to the complexity of the HEA architecture, this could be individual for every aircraft or architecture.

Other aspects might be electromagnetic interference or electromagnetic compatibility due to the required power of the overall aircraft. Voltage levels, and in connection the breakdown voltage of the insulator, are also relevant. On the other hand, the required power and the voltage level define the current, which in the end drives the cross section of the conductor and therefore mass.

\section{Reference Flight Missions}

The requirements and evaluation criteria serve as a framework for the output data that will be generated in the aircraft design. Those parameters depend, e.g., on weather (ambient temperature in particular), on energy management strategies, and also on the flight route and profile. Therefore, various reference flight missions were developed in the frame of FUTPRINT50, so potential markets for the regional aircraft can be analyzed:

- Design Range

- Maximum Range

- Cold Operations

- $\quad$ Extreme Cold Operations

- Hot and High Operations

- Mountainous Terrain

- Island Operations

- $\quad$ STOL Operations

For these missions, an advantageous position on the market may be anticipated for the regional HEA developed within FUTPRINT50. In regions with excellent railway systems, the regional HEA will not be able to prevail due to its limited seat capacity. However, specific markets come into play where no other means of transport can compete. This concerns routes where rough terrain or water lies in between, or infrastructure like railway or road networks are less developed.

The design range criterion can be represented by the route from Edinburgh, United Kingdom to Dublin, Ireland (EDI-DUB). The great circle distance for this route is $338 \mathrm{~km}$. However, all distances of the presented routes have been increased by $7 \%$ to account for possible headwind and 5\% for airways and navigation. This leads to a design range of $380 \mathrm{~km}$, which represents the definition by the TLARs very well. The alternate airport for Dublin is Belfast (BFS), which is located ca. $140 \mathrm{~km}$ north. After adding all contingency reserves, this route represents the defined distance to an alternate airport $(185 \mathrm{~km})$ very well. Figure 12 shows the flight route and its altitude profile. This also includes the flight to the alternate airport and thirty minutes of loiter at 175 knots. It becomes apparent that the reserve is a significant part of the whole flight mission and must not be neglected.

For the investigation of low temperature impacts, a flight route in Iceland is selected. The flight from Reykjavík to Egilsstaðir (RKV-EGS) is a common route serviced by a De Havilland Canada DHC-8. The average temperature at both airports is about ISA - 10 .

In order to account for the effects to the powertrain in even colder temperatures, the flight route from Yakutsk to Vilyuisk (YKS-VYI) in Russia is examined. The average winter temperature can reach up to ISA $-55\left(-40^{\circ} \mathrm{C}\right)$. 

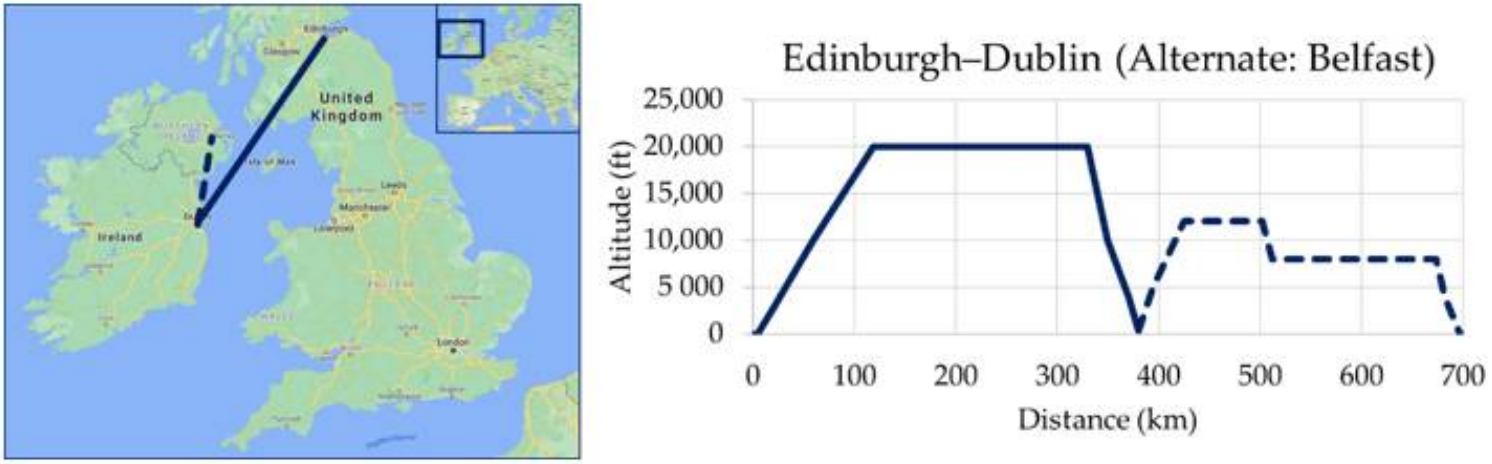

Figure 12. Exemplary flight route and profile of the design range mission EDI-DUB (Edinburgh, United Kingdom to Dublin, Ireland) (including the flight to the alternate BFS (Belfast) and a holding of $30 \mathrm{~min}$ ).

As mentioned earlier, the regional HEA will be able to compete on routes where other means of transport lack required infrastructure. This is also the case in the mountainous terrain from Lima to Ayacucho (LIM-AYP) in Peru. This flight route requires a steep climb right after take-off to reduce detours; this will challenge the climb performance of the aircraft design. Furthermore, a Missed Approach Procedure at an airport elevation of $2720 \mathrm{~m}$ is included on this route.

In order to test the TLAR for hot and high missions, the flight route from Mexico City to Acapulco (MEX-ACA) in Mexico was selected. The elevation of the airport of Mexico City is $2230 \mathrm{~m}$, which translates into a $20 \%$ reduced air density compared to SL. Furthermore, Mexico City shows an average daytime temperature that lies $10^{\circ}$ above ISA conditions.

Island operations describe a mission which restricts refueling to only take place at one airport. This can be simulated by flight operations from São Tomé to Príncipe (TMS-PCP) and back. It must be noted that the distances of each leg may not be simply added up to one round trip. The need for two take-offs and climbs is expected to play a major role on the total energy required.

To account for the STOL capabilities of the aircraft, the flight route from Corvo to Horta (CVU-HOR) in Portugal was included in the list of reference missions. With a flight distance of about $270 \mathrm{~km}$, both airports are located on separate islands in the Azores. The runway in Corvo offers an available take-off run distance of only $800 \mathrm{~m}$. Table 5 shows a summary of the flight mission profiles selected along with each of their specific reasoning.

Table 5. Selection criteria for chosen flight missions.

\begin{tabular}{ccc}
\hline Flight Mission & Route & Special Characteristic \\
\hline Design Range & EDI-DUB & ca. $400 \mathrm{~km}$, competing transport via $2 \mathrm{~h}$-ferry \\
Maximum Range & TJM-NJC & ca. $800 \mathrm{~km}, 13 \mathrm{~h}$ by car, $17 \mathrm{~h}$ by train \\
Cold Ops & RKV-EGS & Temperature ISA -10 \\
Hot and High & MEX-ACA & MEX: Elevation $2230 \mathrm{~m}$, Temperature ISA +10 \\
Extreme Cold Ops & YKS-VYI & Winter temperatures around ISA $-55\left(-40{ }^{\circ} \mathrm{C}\right)$ \\
Mountain Ops & LIM-AYP & After take-off: $3000 \mathrm{~m}$ at $80 \mathrm{~km}, 4500 \mathrm{~m}$ at $150 \mathrm{~km}$ \\
Island Ops & TMS-PCP & Two $200 \mathrm{~km}$-legs without refueling \\
STOL Ops & CVU-HOR & CVU: Runway length $800 \mathrm{~m}$ \\
\hline
\end{tabular}

\section{Figures of Merit}

Within the aircraft design process, numerous unique aircraft configurations are generated, especially in the conceptual design phase. In order to assess those models as objectively as possible, various evaluation criteria, the so-called figures of merit, must be defined. While the TLARs described in Section 2 establish a framework of the aircraft design, the figures of merit quantify how well the design performs within the given evaluation criteria. In general, all quantifiable output parameters of the aircraft design process 
can serve as figures of merit. They are then utilized to rate and compare the configurations on the basis of those parameters. The more design parameters are considered, the better the assessment of the aircraft design might be. However, using a lot of parameters can also make an evaluation less transparent and more complex. Hence, a selection process for meaningful, quickly graspable figures of merit is important. This is described in Section 4.1.

While the separate parameters can compare isolated disciplines of the aircraft design, a combination of these parameters can form one aircraft-level figure of merit which rates the entire aircraft design. By means of a calculation method described in Section 4.2, the aircraft-level figure of merit is constructed as a number between 0 and 1 . On that scale, a better design—based on the evaluation criteria set—-translates into a higher score.

\subsection{Identification of Figures of Merit}

To find the most suitable figures of merit, all parameters generated in the aircraft design are processed through different criteria [22]. These criteria form a filter that excludes figures of merit that do not affect the overall evaluation of the aircraft in a significant way and are, therefore, discarded. The filter comprises four criteria:
1. Limitations that are defined by TLARs
2. Design parameters that are fixed
3. Parameters that do not change significantly between different designs
4. Parameters that are expressed through higher-level ones.

The first criterion discards figures of merit that do not influence the assessment because of limitations by the TLARs. An example for this criterion is the parameter of aviation induced cloudiness. As shown in Section 2, a maximum operating cruise altitude of 25,000 ft was chosen for the regional aircraft developed within the FUTPRINT50 project. Since aviation induced cloudiness is mainly expected to form in altitudes higher than that [16], this figure of merit can be discarded.

Fixed design parameters act as second criterion. Some parameters must remain unchanged during a design process. For example, the maximum range is a hard requirement stated by the airlines. Falling short of it is not an option. However, exceeding it will make the design not necessarily better either; the design may become less efficient on shorter ranges because of an increased operating mass empty.

The third criterion filters out parameters that do not change significantly. This may be valid for parameters that are estimated by engineers or parameters that only vary in case of major technology changes. Switching from conventional jet fuel to hydrogen will impact the ground handling and servicing for every aircraft design similarly. This is why it can be neglected.

The last criterion discards any figure of merit that can be expressed by a higher-level one. As an example, cruise speed is often defined as a figure of merit because it can have an influence on the number of possible dispatches. However, it is also interconnected with fuel consumption and many other characteristics. All of those aspects can be combined within the DOCs.

Additional parameters in regard to the entire life cycle, like $\mathrm{CO}_{2}$ emissions of the production or end-of-life phase, are not considered. However, they can be easily included afterwards due to the flexibility of the calculation method of the figure of merit.

This selection process leads to seven figures of merit listed in Table 6, where they are divided into three categories. These seven meaningful parameters evaluate the quality of the regional HEA developed within FUTPRINT50 and can be used as a basis for the assessment of future concepts in this aircraft category. The separate figures of merit will be explained in more detail in the following. 
Table 6. Summary of figures of merit selected in the frame of FUTPRINT50.

\begin{tabular}{ccc}
\hline Environmental Aspects & Airline Desirability & $\begin{array}{c}\text { Introduction of Hybrid- } \\
\text { Electric Aircraft }\end{array}$ \\
\hline $\mathrm{CO}_{2}$ emissions & Direct operating costs & Development risks \\
$\mathrm{NO}_{\mathrm{X}}$ emissions & & Certification challenges \\
Noise emissions & Production aspects \\
\hline
\end{tabular}

The Environmental Aspects that are chosen for the figures of merit compare to the goals set in Flightpath 2050. As the $\mathrm{CO}_{2}$ emissions of an aircraft strongly depend on fuel flow, energy management strategies have a major influence on this part of the figures of merit. Another environmental figure of merit is the emission of $\mathrm{NO}_{\mathrm{X}}$. It can mainly be lowered by improving the combustion characteristics of the engine. While its atmospheric effect is important to consider because of ozone forming, it is also a relevant pollutant in the vicinity of airports [23].

The same issue corresponds as well to the noise emissions. Noise is a very important aspect in order to ensure the health and well-being of citizens living close to airports. Although noise is difficult to analyze in the early design process, engineers can roughly estimate it by focusing on components protruding from the aircraft profile like landing gear or flaps. Another key element is the positioning of propulsion components and potential shielding like a ducted fan would offer.

Major contributions to these aspects can be provided by an optimum energy management strategy which is adaptive to the current state of operation. This offers the potential to reduce emissions overall or just in particular flight segments close to the ground.

Operators are the main drivers for aircraft specifications, and appealing to them is of major importance for every design. Since cost is an essential parameter in the airline industry, the DOCs are the main driver of the Airline Desirability.

The DOCs are divided into five segments which consist of capital costs, maintenance costs, energy costs, crew costs, and (navigation) fees. Capital costs are expected to rise for a new HEA because of higher development efforts. On the other hand, energy and maintenance costs are expected to decrease because of lower energy costs for HEA and less complex maintenance in the long run [24]. The energy costs are highly dependent on many parameters like cruise speed or energy management strategies, all of which are defined by the reference flight missions. While crew costs are expected to be comparable to the ones on conventional aircraft, the navigation and landing fees might decrease because of environmental rewards.

Beside operating costs, the potential of generating income is an important aspect for airlines as well. Here however, it is assumed to stay the same as seat capacity and passenger comfort remain unchanged. Though, it may be included in further enhanced models.

The figures of merit in the category Introduction of Hybrid-Electric Aircraft cover the risks in development as well as the expected challenging certification process and overall production aspects. The first item represents the risks for the manufacturer developing the HEA. This includes challenges that might occur in the design process of not only the overall aircraft, but also of all required components and subsystems. To address these topics, an estimation is made in relation to the technology readiness level of identified key technologies. Furthermore, if required, infrastructure needs are also considered. This could be the case for hydrogen fuel as well as required infrastructure to either swap batteries and recharge them at the airport or charge the batteries within the airplane.

Certification is the second part within this category. Currently, the CS-25 from the European Union Aviation Safety Agency (EASA) offers no guidelines on how to certify hybrid-electric aircraft. By assessing the complexity of the system, an estimation can be made about the amount of testing required for certification. Furthermore, adding novel propulsion concepts like distributed electric propulsion will increase complexity even more and therefore require additional verification. 
Lastly, the selection of material and the application of processes also impose risks on different designs. Again, the newer and more complex the technology, the higher the overall risk for unforeseen difficulties in production. All these criteria are difficult to quantify and must oftentimes be objectively estimated by the engineer.

\subsection{Calculation of the Aircraft-Level Figure of Merit}

With the selected figures of merit, a new process becomes necessary: The separate figures of merit presented before must be merged into one single aircraft-level figure of merit which evaluates the entire aircraft configuration [22]. This helps by comparing different concepts and identifying which of the designs is the most promising one for further development. The scheme of this method is shown in Figure 13.

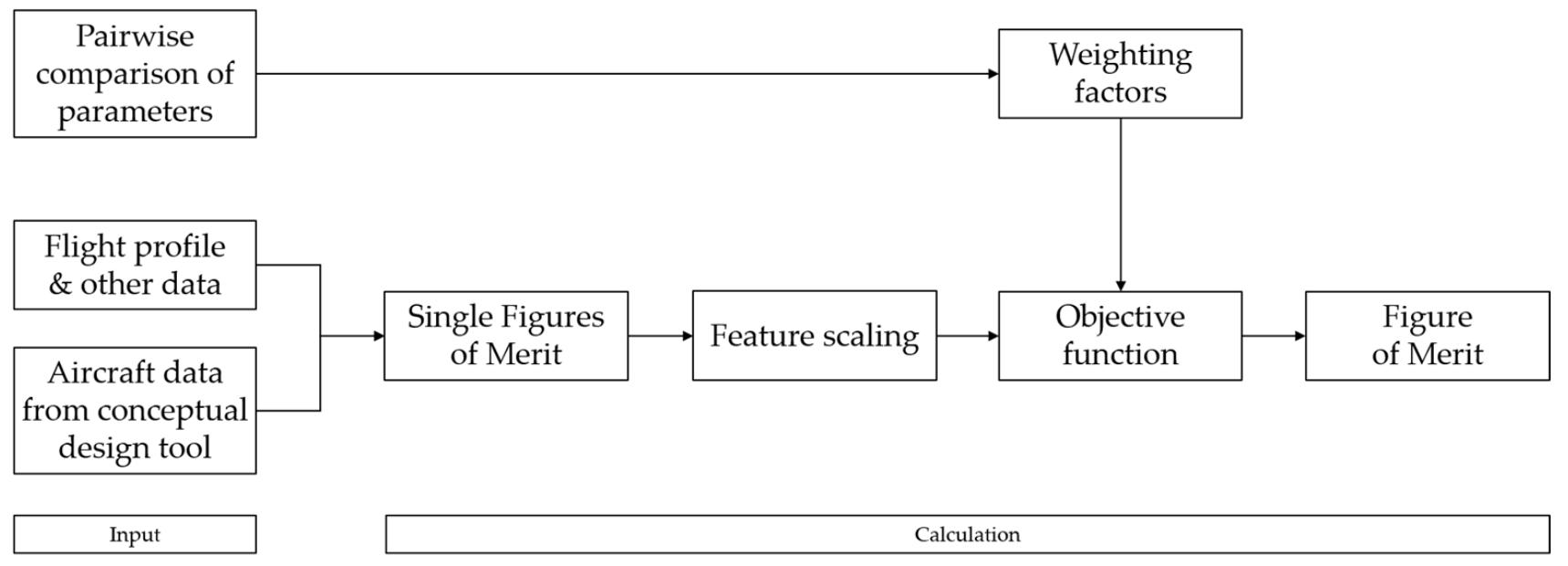

Figure 13. Calculation method for the figure of merit.

The first step of the calculation method consists of combining two major input data. The design tool provides all required aircraft data like dimensions, masses, and aerodynamics. Further input contains data about the flight profile, energy management strategies, ambient conditions, etc.; this depends on the chosen reference mission. The following module, Single Figures of Merit, calculates the seven single figures of merit that were previously selected. As those separate figures of merit are all given out in their individual unit, they need to be feature scaled so they can be combined into one. Feature scaling is a method which removes all units and resizes all the different values of the figures of merit onto a rating scale. This is done by analyzing all values of each parameter and assigning the scores 0 and 1 to the lowest or highest value. The remaining values are scaled correspondingly. However, it is important to note that the lowest score does not necessarily coincide with the lowest value. This is because a lower value in emissions, for example, will lead to a higher score on the assessment scale.

Furthermore, the resulting equation also consists of weighting factors. They are mostly generated by a pairwise comparison in a table. In the case of the different emissions of greenhouse gases, however, the parameters are weighted by their different impacts on the environment. This constructed equation forms the so-called objective function. It consists of weighted and normalized parameters which are then combined into the aircraft-level figure of merit. The flexibility of this weighting allows us to identify designs with different focusses, for example, prioritizing environmental aspects over costs or vice versa. In the end, various sets of weighting factors can be applied, where each set represents a specific focus that shall be analyzed. This process leads to a single number, which represents the figure of merit on the aircraft level. This number will then be used to assess all the aircraft designs that need to be compared.

Dividing the parameters into different categories and sticking to that strict workflow has the advantage that the structure of the figures of merit is established in a modular way. 
For example, a function of power, specific fuel consumption, and time quantifies the $\mathrm{CO}_{2}$ emissions, which merge into the environmental aspects. So, the modular approach allows for building a figure of merit that consists of others, merging into the single aircraft-level figure of merit. This means that if any outcome of a figure of merit is unclear, it is always possible to go one level deeper to understand the characteristics of that specific figure of merit. This provides transparency, traceability, and plausibility. Another advantage of the modular approach is the simple implementation of modifications. When an additional figure of merit is identified, it can be added by changing only one module of the entire workflow. This allows an easy integration of figures that were previously discarded-it is also thinkable to select a modular approach within the code. For example, the maximum altitude or cruise altitude could be analyzed and based on this value, and contrails are included or discarded in the environmental aspects.

\section{Conclusions}

Within this work, requirements for sustainable regional aviation and their reasoning within the FUTPRINT50 framework have been presented. Moreover, the figures of merit were displayed which validate to what extent the defined requirements are fulfilled. The $\mathrm{V}$-model of systems engineering builds the framework for the overall project and ensures a successful "end product". A mission statement defines the value that is added for the stakeholders and outlines the overall system to be designed. Here, the focus was set on the European citizen and improvements to their life quality by reducing emissions of pollutants and noise.

With the help of the mission statement, the top-level aircraft requirements were defined. These requirements set the criteria that must be fulfilled by the system to be designed. Considering not only environmental aspects, but also the performance of the system should satisfy the operators and stakeholders. These specifications ensure that the aircraft to be developed can occupy its planned niche within the system of systems. In addition, we took a closer look on the defined reserve distance and range requirements. The study for the reserve policy shows that-including a safety factor-more than $95 \%$ of the investigated commercial airports have at least one alternate within $185 \mathrm{~km}$. En route alternates are expected to be less problematic if the hybrid-electric aircraft is sized properly with enough redundancy for the different energy sources. The study has shown that most parts of the EU can be covered, and more than 10,000 connections are possible; this represents around $15 \%$ of possible connections within Europe above $250 \mathrm{~km}$. In the future, further analyses could be performed for other regions of the world: Mountainous regions or island operations might be of particular interest. Examples could be the Andes or the Himalaya for the former, and the Caribbean or Southeast Asia for the latter.

After stating the requirements-following the iterative process of the V-model-the figures of merit were defined. Besides verifying whether stakeholder needs and requirements are met, they aim to identify the best design from many. This is done in three key categories that are most influential to the goals of the project. Seven parameters divided into environmental, economic, and technical aspects are rated for all investigated aircraft designs. This analysis reveals the quality of the aircraft in comparison to other designs. Furthermore, a method was created that provides a modular structure of all separate figures of merit. This ensures flexibility and allows easy changes to the composition of the aircraft-level figure of merit.

The TLARs and the figures of merit must be tested in consistent scenarios. To achieve this, different reference missions were defined, each one specific to test a key aspect of the requirements. With this, a focus on different scenarios can be set in the future depending on the expected size or relevance of potential and existing markets.

Author Contributions: Conceptualization, D.E., N.M., E.W., and R.R.; software, D.E., D.B., and I.G.; investigation, D.E., N.M., E.W., D.B., I.G., and R.R.; writing-original draft preparation, D.E., N.M., and D.B.; writing—review and editing, D.E., N.M., E.W., D.B., I.G., R.R., and A.S.; supervision, A.S.; 
project administration, D.B.; funding acquisition, D.B., R.R., A.S. All authors have read and agreed to the published version of the manuscript.

Funding: The research leading to these results has received funding from the European Union's Horizon 2020 Research and Innovation program under Grant Agreement No 875551.

Institutional Review Board Statement: Not applicable.

Informed Consent Statement: Not applicable.

Data Availability Statement: Results not available, raw data is cited in text.

Acknowledgments: We thank all researchers and collaborators of the entire FUTPRINT50 Consortium, namely University of Stuttgart, Cranfield University, Airholding S.A., TU Delft, ADSE, CEA, EASN, Unicusano, Embraer, TsAGI, GosNIIAS, CIAM, NRC, and MAI, for their valuable input.

Conflicts of Interest: The funders had no role in the design of the study; in the collection, analyses, or interpretation of data; in the writing of the manuscript, or in the decision to publish the results.

$\begin{array}{ll}\text { Abbreviations } \\ \text { ATAG } & \text { Air Transport Action Group } \\ \text { CORSIA } & \text { Carbon Offsetting and Reduction Scheme for International Aviation } \\ \text { CS } & \text { Certification Specification } \\ \text { DOC } & \text { Direct Operating Costs } \\ \text { EASA } & \text { European Union Aviation Safety Agency } \\ \text { EIS } & \text { Entry Into Service } \\ \text { EU } & \text { European Union } \\ \text { FL } & \text { Flight Level } \\ \text { HEA } & \text { Hybrid-Electric Aircraft } \\ \text { ICAO } & \text { International Civil Aviation Organization } \\ \text { ISA } & \text { International Standard Atmosphere } \\ \text { MTOM } & \text { Maximum Take-Off Mass } \\ \text { OEI } & \text { One Engine Inoperative } \\ \text { SAF } & \text { Sustainable Aviation Fuel } \\ \text { SL } & \text { Sea Level } \\ \text { STOL } & \text { Short Take-Off and Landing } \\ \text { TLAR } & \text { Top-Level Aircraft Requirements } \\ \text { TOFL } & \text { Take-Off Field Length } \\ \text { UN } & \text { United Nations }\end{array}$

\section{References}

1. Air Transport Action Group. Aviation: Benefits Beyond Borders. 2020 Report. 2020. Available online: https://aviationbenefits. org/media/167143/abbb20_full.pdf (accessed on 10 November 2020).

2. International Civil Aviation Organization. 2019 Environmental Report. Aviation and Environment. 2019. Available online: https: / / www.icao.int/environmental-protection/Documents/ICAO-ENV-Report2019-F1-WEB\%20(1).pdf (accessed on 9 March 2020).

3. Lee, D.; Fahey, D.; Skowron, A.; Allen, M.; Burkhardt, U.; Chen, Q.; Doherty, S.; Freeman, S.; Forster, P.; Fuglestvedt, J.; et al. The contribution of global aviation to anthropogenic climate forcing for 2000 to 2018. Atmos. Environ. 2020, 244, 117834. [CrossRef] [PubMed]

4. Sparrow, V.; Gjestland, T.; Guski, R.; Richard, I.; Basner, M. Aviation Noise Impacts White Paper: State of the Science 2019: Aviation Noise Impacts. In 2019 Environmental Report: Aviation and Environment; ICAO: Montreal, QC, Canada, 2019 ; pp. 44-61.

5. European Commission. Flightpath 2050. Europe's Vision for Aviation; Maintaining Global Leadership and Serving Society's Needs; Report of the High-Level Group on Aviation Research; Publications Office of the European Union: Luxembourg, 2011; ISBN 978-92-79-19724-6.

6. European Commission. The European Green Deal COM(2019) 640. 2019. Available online: https: / / eur-lex.europa.eu/resource. html?uri=cellar:b828d165-1c22-11ea-8c1f-01aa75ed71a1.0002.02/DOC_1\&format=PDF (accessed on 20 November 2020).

7. United Nations. Transforming Our World: The 2030 Agenda for Sustainable Development. A/RES/70/1. Available online: https: / / sustainabledevelopment.un.org/content/documents / 21252030\%20Agenda\%20for\%20Sustainable\%20Development\% 20web.pdf (accessed on 10 November 2020).

8. Avions de Transport Régional. ATR Turboprop Market Forecast 2018-2037. Available online: https://1tr779ud5r1jjgc938wedppwwpengine.netdna-ssl.com/wp-content/uploads/2020/07/1011_makretforecast_digital_151.pdf (accessed on 1 February 2021). 
9. $\quad$ Eisenhut, D.; Windels, E.; Reis, R.; Bergmann, D.; Ilário, C.; Palazzo, F.; Strohmayer, A. Foundations towards the future: FutPrInt50 TLARs an open approach. IOP Conf. Ser. Mater. Sci. Eng. 2021, 1024, 12069. [CrossRef]

10. EASA. Certification Specifications and Acceptable Means of Compliance for Large Aeroplanes CS-25. Amendment 25. 2020. Available online: https:/ / www.easa.europa.eu/sites/default/files/dfu/cs-25_amendment_25.pdf (accessed on 11 November 2020).

11. International Civil Aviation Organization. Annex 14 to the Convention on International Civil Aviation. Aerodromes, 8th ed.; Aerodrome Design and Operations: Montreal, QC, Canada, 2018; Volume 1, ISBN 978-92-9258-483-2.

12. Embraer S.A. EMB-145. Airport Planning Manual. 2019. Available online: https://www.flyembraer.com/irj/go/km/docs/ download_center/Anonymous/Ergonomia/Home\%20Page/Documents/APM_145.pdf (accessed on 10 December 2020).

13. Bombardier Inc. DHC-8-300. Airport Planning Manual. 2001. Available online: https://eservices.aero.bombardier.com/wps/ portal/eServices/Public/AirportEmergencyPublication (accessed on 10 December 2020).

14. Patterson, M.D.; Borer, N.K. Approach Considerations in Aircraft with High-Lift Propeller Systems. 2017. Available online: https:/ / ntrs.nasa.gov/api/citations/20170005869/downloads/20170005869.pdf (accessed on 30 November 2020).

15. Avions de Transport Régional. ATR 42-600 Fact Sheet. Available online: http://1tr779ud5r1jjgc938wedppw-wpengine.netdna-ssl com/wp-content/uploads/2020/07/Factsheets_-_ATR_42-600.pdf (accessed on 11 November 2020).

16. Kärcher, B. Formation and radiative forcing of contrail cirrus. Nat. Commun. 2018, 9. [CrossRef] [PubMed]

17. Eurostat. Air Transport Measurement: 2019 List of Reporting Airports Covered by Commission Regulation 1358/2003. Available online: https:/ / ec.europa.eu/eurostat/cache/metadata/Annexes/avia_pa_esms_an5.docx (accessed on 18 November 2020).

18. Garrecht Avionik GmbH. Airport List I openAIP. Available online: https://www.openaip.net/airports (accessed on 1 December 2020).

19. Halpern, N.; Bråthen, S. Impact of airports on regional accessibility and social development. J. Transp. Geogr. 2011, 19, 1145-1154. [CrossRef]

20. International Civil Aviation Organization. Annex 6 to the Convention on International Civil Aviation-Operation of Aircraft-Part I-International Commercial Air Transport-Aeroplanes, 11th ed.; ICAO: Montreal, QC, Canada, 2018; ISBN 978-92-9258-473-3.

21. Geiß, I.; Strohmayer, A. Operational Energy and Power Reserves for Hybrid-Electric and Electric Aircraft. Deutscher Luft-und Raumfahrtkongress 2020 2021. [CrossRef]

22. Moebs, N.; Eisenhut, D.; Bergmann, D.; Strohmayer, A. Selecting figures of merit for a hybrid-electric 50-seat regional aircraft. IOP Conf. Ser. Mater. Sci. Eng. 2021, 1024, 12071. [CrossRef]

23. Derwent, R.; Collins, W.; Johnson, C.; Stevenson, D. Global ozone concentrations and regional air quality. Environ. Sci. Technol. 2002, 36, 379A-382A. [CrossRef] [PubMed]

24. Hoelzen, J.; Liu, Y.; Bensmann, B.; Winnefeld, C.; Elham, A.; Friedrichs, J.; Hanke-Rauschenbach, R. Conceptual Design of Operation Strategies for Hybrid Electric Aircraft. Energies 2018, 11, 217. [CrossRef] 